\title{
Thermal dye double indicator dilution measurem
lung water in man: comparison with gravimetric measurements
}

\author{
FREDERICK G MIHM, THOMAS W FEELEY, STUART W JAMIESON \\ From the Departments of Anesthesia and Cardiovascular Surgery, Stanford University Medical Center, \\ Stanford, California, USA
}

ABSTRACT The thermal dye double indicator dilution technique for estimating lung water waso compared with gravimetric analyses in nine human subjects who were organ donors. As observed in animal studies, the thermal dye measurement of extravascular thermal volume (EVTV) consis-c tently overestimated gravimetric extravascular lung water (EVLW), the mean (SEM) differencec being $3.43(0.59) \mathrm{ml} / \mathrm{kg}$. In eight of the nine subjects the EVTV $-3.43 \mathrm{ml} / \mathrm{kg}$ would yield an estimate of EVLW that would be from $3.23 \mathrm{ml} / \mathrm{kg}$ under to $3.37 \mathrm{ml} / \mathrm{kg}$ over the actual value EVLW at the $95 \%$ confidence limits. Reproducibility, assessed with the standard error of the mean percentage, suggested that a $15 \%$ change in EVTV can be reliably detected with repeated measurements. One subject was excluded from analysis because the EVTV measurement grossly underestimated its@ actual EVLW. This error was associated with regional injury observed on gross examination of the lung. Experimental and clinical evidence suggest that the thermal dye measurement provides å reliable estimate of lung water in diffuse pulmonary oedema states.

Clinical medicine currently has no reasonably quantitative method of evaluating pulmonary oedema. The constellation of signs and symptoms (crackles, dyspnoea, tachypnoea, cardiac gallops, tachycardia, wheezing, and pink frothy sputum) are either nonspecific or non-quantitative. Portable chest radiographs are often too insensitive to detect changes in lung water. ${ }^{1}$ Changes in arterial oxygenation and lung compliance occur with pulmonary oedema, but are non-specific and change in other acute lung diseases, such as atelectasis or infection. The development of a technique for measuring extravascular lung water (EVLW) in vivo might prove to be clinically valuable as well as an important research tool. Such a technique would be particularly useful in the diagnosis of non-cardiogenic pulmonary oedema, where changes in alveolar-capillary membrane permeability occur. It might also be important as a measure of response to drugs, such as diuretics, which have considerable hazards (hypovolaemia, renal failure) if used inappropriately or arbitrarily without any

Address for reprint requests: Dr Frederick G Mihm, Department of Anesthesia (S-278), Stanford University School of Medicine, Stanford, California 94305, USA.

Accepted 27 August 1986 quantifiable benefit. This study sought to compare the accuracy of the thermal dye double indicator measurement ${ }^{2}$ of extravascular thermal volume (EVTV) compared with that of gravimetrically determined lung water measurements in human subjects.

\section{Methods}

After institutional ethical approval and family consent, nine subjects who had been determined to beo brain dead and had been accepted as organ donors were studied before removal of the organs. Eight hado been victims of a motor vehicle accident and one of a gunshot wound to the head. One subject (No 8) hado frothing pulmonary oedema at the time of study.

A 4F internal jugular central venous catheter and an $5 \mathrm{~F}$ thermistor tipped femoral artery catheter were ${ }_{O}^{\omega}$ placed by the Seldinger technique. Arterial blood was sampled for blood gas analysis 20 minutes after the inspired oygen had been adjusted to $100 \%$. EVTV measurements were made by injecting $10 \mathrm{ml}$ of cold ${ }_{T}^{-}$ $\left(0^{\circ} \mathrm{C}\right)$ indocyanine green dye $(4 \mathrm{mg})$ rapidly into the superior vena cava. Blood was withdrawn $(30 \mathrm{ml} / \mathrm{min}) \overrightarrow{\mathbb{D}}$ by syringe pump (Sage 950 ) through a densitometer $\frac{O}{\mathbb{P}}$ cuvette (Waters D-402A) attached to the femoral
catheter. 
Curves of both femoral blood temperature and dye concentration versus time were recorded. A small computer (Edwards 9310) simultaneously processed these data and derived EVTV by the mean transit times of the two indicators and cardiac output by the thermodilution curve. To avoid recirculation, once the curves fall to $30 \%$ of peak values, the remainder of the downslope is extrapolated on the assumption of an exponential decay. A mean of several measurements was used for comparison with gravimetric data.

After removal of organs for transplantation (heart, kidneys) both lungs were removed and weighed. The lungs were homogenised with an approximately equal volume of water in a commercial blender (Waring 32BL39), and then centrifuged ( $10000 \mathrm{~g}$ for $30 \mathrm{~min})$. Aliquots of blood (drawn when the organs were removed), lung homogenate, and homogenate supernatant were weighed before and after drying at $80^{\circ} \mathrm{C}$ to constant weight. Standard formulae were used to calculate extravascular lung water and dry weight (EVLW and EVDW). ${ }^{34}$

Data are expressed as means, with accuracy, or the degree of agreement of the EVLW, determined by comparing the differences between EVLW and EVTV against their means. ${ }^{5}$

\section{Results}

The human lung gravimetric data are shown in table 1. The mean (SEM) EVLW in the six subjects (Nos 1-6) who were apparently normal was 4.08 $(0.43) \mathrm{ml} / \mathrm{kg}$ body weight. The EVDW for all nine subjects studied was $1.27(0.08) \mathrm{g} / \mathrm{kg}$ body weight.

Table 2 gives information on the subjects and physiological data obtained at the time of EVTV measurements. The time between EVTV measurement and lung removal was less than 260 minutes in all patients (mean (SEM) 164 (21) min). A graph of the data, EVTV versus EVLW, is shown in figure 1. Eight of nine data points lie in a linear grouping above the line of identity. There is one obvious outlyer who was excluded from statistical analysis and will be discussed later. To examine the degree of agreement between the measures of EVLW and EVTV, the difference between EVLW and EVTV was compared with the average of these two measures of lung water $((E V L W+E V T V) / 2$ determined for each subject $)$ (fig 2). The mean difference between EVLW and EVTV (with subject 9 excluded) was 3.43 $(0.59) \mathrm{ml} / \mathrm{kg}$. The limits of agreement suggest that the EVTV -3.43 will be from $3.23 \mathrm{ml} / \mathrm{kg}$ under to $3.37 \mathrm{ml} / \mathrm{kg}$ over the EVLW at the $95 \%$ confidence level. Although this degree of agreement may not be considered acceptable for clinical application of the thermal dye technique, EVTV is highly associated with EVLW, as suggested by figure 1 and proved by linear regression analysis (EVTV $=1.3 \mathrm{EVLW}+$ $1.8 \mathrm{ml} / \mathrm{kg} ; \mathrm{r}=0.98, \mathrm{p}<0.001(\mathrm{n}=8)$. This degree of association would allow estimation of actual lung water values by this relationship as well. Since the slope of the regression equation (1.3) is significantly greater than $1(t=2.75, \mathrm{p}<0.05)$, estimating EVLW by the regression equation will be more reasonable than using the mean difference analysis (where the slope of regression is assumed to be 1). Table 3 shows estimated EVLW values obtained by using the mean difference versus the regression equation. Estimates of EVLW obtained by these two methods become more disparate at low and high values, where estimates derived from the regression equation appear more consistent with the data obtained in this study (fig 1).

Reproducibility was assessed by dividing the standard error of the mean (SEM) by the average EVTV in each series of EVTV measurements (3-6 measurements per series) and expressing this as a percentage. ${ }^{6}$ The average SEM $\%$ was $4 \cdot 4 \%$, which compares favourably with the $2 \cdot 0-5 \cdot 0 \%$ reported for thermodilution cardiac output measurements. The calculations suggested that a $15 \%$ change in EVTV would indicate a real change in a patient $(95 \%$ confidence level). Since our current clinical diagnosis of pulmonary oedema requires an estimated increase

Table 1 Gravimetric data on human lung

\begin{tabular}{|c|c|c|c|c|}
\hline $\begin{array}{l}\text { Subject } \\
\text { No }\end{array}$ & $\begin{array}{l}\text { Body } \\
\text { weight }(\mathrm{kg})\end{array}$ & $\begin{array}{l}\text { Lung } \\
\text { weight }(\mathrm{g} / \mathrm{kg})\end{array}$ & $\begin{array}{l}E V L W \\
(\mathbf{m l} / \mathbf{k g})\end{array}$ & $\begin{array}{l}E V D W \\
(\boldsymbol{g} / \mathbf{k g})\end{array}$ \\
\hline $\begin{array}{l}1 \\
2 \\
3 \\
4 \\
5 \\
6 \\
7 \\
8 \\
9\end{array}$ & $\begin{array}{l}61 \cdot 0 \\
96 \cdot 4 \\
60 \cdot 0 \\
74 \cdot 7 \\
54 \cdot 5 \\
81 \cdot 0 \\
80 \cdot 5 \\
60 \cdot 0 \\
63 \cdot 0\end{array}$ & $\begin{array}{r}10.25 \\
8.45 \\
11 \cdot 29 \\
7.84 \\
8.66 \\
13.05 \\
15.18 \\
28.48 \\
22.83\end{array}$ & $\begin{array}{r}2.89 \\
3.16 \\
3.49 \\
4.65 \\
4.82 \\
5.48 \\
7.40 \\
16.61 \\
17 \cdot 21\end{array}$ & $\begin{array}{l}1.41 \\
0.92 \\
1.08 \\
0.94 \\
1.36 \\
1.39 \\
1.30 \\
1.30 \\
1.70\end{array}$ \\
\hline
\end{tabular}

EVLW-extravascular lung water; EVDW-extravascular dry weight. 
Table 2 Information on patients and physiologic data obtained with EVTV measurements*

\begin{tabular}{|c|c|c|c|c|c|c|c|}
\hline $\begin{array}{l}\text { Subject } \\
\text { No }\end{array}$ & $\begin{array}{l}\text { Age } \\
(y)\end{array}$ & $\begin{array}{l}\mathrm{PaO}_{2} \\
(\mathrm{~mm} \mathrm{Hg})\end{array}$ & $\begin{array}{l}\mathrm{AaDO}_{2} \\
(\mathrm{~mm} \mathrm{Hg})\end{array}$ & $\begin{array}{l}C V P \\
(m m H g)\end{array}$ & $\begin{array}{l}\text { Cardiac } \\
\text { output } \\
(I / \mathrm{min})\end{array}$ & $\begin{array}{l}E V L W \\
(m l / k g)\end{array}$ & $\begin{array}{l}E V T V \\
(m l / k g)\end{array}$ \\
\hline $\begin{array}{l}1 \\
2 \\
3 \\
4 \\
5 \\
6 \\
7 \\
8 \\
9\end{array}$ & $\begin{array}{l}18 \\
34 \\
21 \\
23 \\
14 \\
28 \\
21 \\
22 \\
15\end{array}$ & $\begin{array}{r}457 \\
377 \\
425 \\
252 \\
548 \\
186 \\
305 \\
84 \\
146\end{array}$ & $\begin{array}{l}212 \\
297 \\
259 \\
424 \\
129 \\
473 \\
368 \\
674 \\
518\end{array}$ & $\begin{array}{r}14 \\
6 \\
7 \\
12 \\
2 \\
3 \\
9 \\
13 \\
13\end{array}$ & $\begin{array}{l}6 \cdot 4 \\
8 \cdot 5 \\
7 \cdot 0 \\
8 \cdot 7 \\
4 \cdot 8 \\
7 \cdot 2 \\
6 \cdot 1 \\
4 \cdot 3 \\
4 \cdot 7\end{array}$ & $\begin{array}{r}2 \cdot 89 \\
3 \cdot 16 \\
3 \cdot 49 \\
4 \cdot 70 \\
4 \cdot 82 \\
5 \cdot 48 \\
7 \cdot 40 \\
16 \cdot 61 \\
17 \cdot 20\end{array}$ & $\begin{array}{r}7 \cdot 5 \\
6 \cdot 0 \\
6 \cdot 0 \\
6 \cdot 1 \\
7 \cdot 8 \\
7 \cdot 9 \\
11 \cdot 7 \\
23 \cdot 2 \\
8 \cdot 1\end{array}$ \\
\hline
\end{tabular}

$\mathrm{PaO}_{2}$-arterial oxygen tension with $\mathrm{FiO}_{2}=1 \cdot 0 ; \mathrm{AaDO}_{2}$-alveolar-arterial oxygen tension difference with Fio $=1 \cdot 0 ; \mathrm{CVP}-$ central venous $\AA$ pressure; EVLW - extravascular lung water by gravimetric measurement; EVTV-extravascular thermal volume by thermal dye double indicator dilution.

Conversion: Traditional SI units-Pressure: $1 \mathrm{~mm} \mathrm{Hg} \approx 0.133 \mathrm{kPa}$.

in lung water of $300-500 \%$, EVTV measurements may provide more sensitive information than has previously been available.

In the remaining subject (No 9) there was a considerable underestimation of lung water by the EVTV measurement $(E V T V=8.1 \mathrm{ml} / \mathrm{kg}$ versus EVLW = $17.2 \mathrm{ml} / \mathrm{kg}$ ). The EVTV measurement predicted by the linear regression data would have been $24.3 \mathrm{ml} / \mathrm{kg}$. This subject did not appear different from the others we studied in regard to age, weight, cardiac output, or time from EVTV measurement to removal of the lung $(135 \mathrm{~min})$. We did, however, note on removal of the lungs that there was remarkably heavy

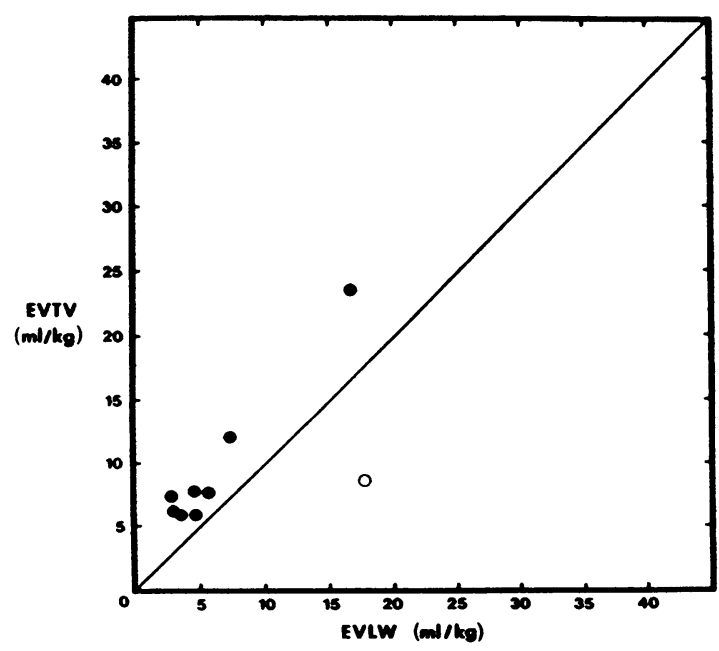

Fig 1 The thermal-dye measurement of extravascular thermal volume (EVTV) plotted against gravimetric determination of extravascular lung water $(E V L W)$ in the nine subjects studied. One subject (open circle) was excluded from statistical analysis. The line of identity is shown. haemorrhagic consolidation of the left lobe. The ${ }_{C}^{-}$ gross appearance of the rest of the lung was normal.g

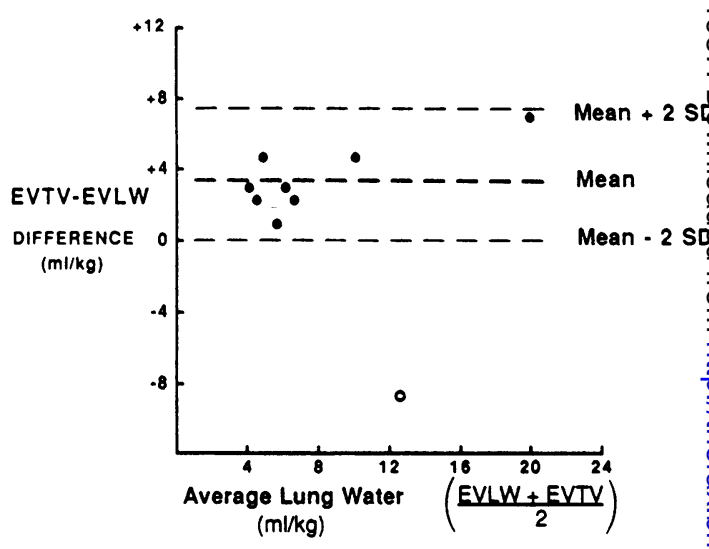

Fig 2 The difference between extravascular thermal volume (EVTV) and extravascular lung water (EVLW) is shown versus the average lung water measurement of both methods $(E V L W+E V T V) / 2$. All units are in $\mathrm{ml} / \mathrm{kg}$ body weight. The lines drawn represent the mean $E V T V-E V L W$ difference, + and $-S D \times 2$. The open circle represents subject 9 which was excluded from statistical analysis.

Table 3 Extravascular lung water ( $E V L W$ ) estimated from $\mathrm{N}$ extravascular thermal volume (EVTV) by two methods

\begin{tabular}{|c|c|c|}
\hline \multirow[b]{2}{*}{$\begin{array}{l}E V T V \\
(\mathrm{ml} / \mathrm{kg})\end{array}$} & \multicolumn{2}{|c|}{ Estimated EVLW } \\
\hline & $\begin{array}{l}\text { By mean } \\
\text { difference }\end{array}$ & $\begin{array}{l}\text { By } \\
\text { regression }\end{array}$ \\
\hline $\begin{array}{r}5.0 \\
10.0 \\
15.0 \\
25.0\end{array}$ & $\begin{array}{r}1.6 \\
6 \cdot 6 \\
11 \cdot 6 \\
21 \cdot 6\end{array}$ & $\begin{array}{r}2.5 \\
6.3 \\
10.2 \\
17.8\end{array}$ \\
\hline
\end{tabular}




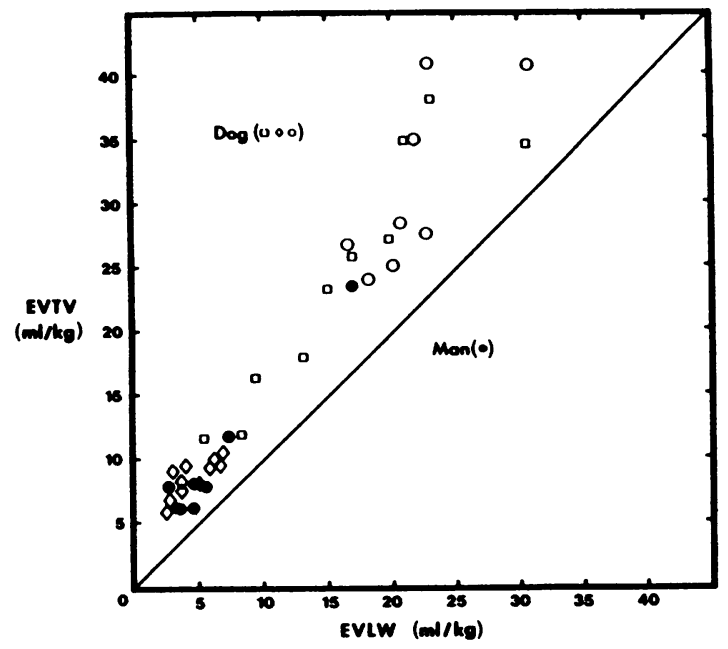

Fig 3 Data (closed circles) shown in Figure 1 are presented together with previously published animal (dog) data, ${ }^{314}$ comparing EVTV with EVLW. Animal data shown include normal controls (open diamonds $\diamond, n=11$ ); hydrostatic pulmonary oedema (open squares $\square, n=10$ ); and oleic acid induced pulmonary oedema (open circles $\bigcirc, n=8$ ). The line of identity is shown. All measurements of EVTV $>23 \mathrm{ml} / \mathrm{kg}$ was associated with frothing pulmonary oedema.

\section{Discussion}

Of the various methods for measuring lung waterthoracic impedance, ${ }^{7}$ gas inhalation, ${ }^{8}$ nuclear imaging, ${ }^{9}$ and double indicator dilution ${ }^{10}$ - the last technique as modified by Lewis may provide an - acceptable combination of clinical utility and accuracy. Lewis suggested using heat and indocyanine green dye combined with a microprocessor for rapid calculation and showed that repeated measurements of EVTV could easily be made at the bedside. ${ }^{2}$ Accuracy of this technique in diffuse oedema states has been assessed in several animal studies comparing the thermal dye double indicator dilution measurement of extravascular thermal volume with gravimetric determination of extravascular lung mass and lung water. The thermal indicator consistently overestimates actual EVLW because of equilibration with dry lung mass, vascular walls, and cardiac chambers; but the relationship is linear throughout all degrees of pulmonary oedema, including alveolar flooding. ${ }^{3}$ All experiments, except two that investigated the effect of pulmonary vascular embolisation, ${ }^{11} 12$ have showed excellent linear correlation of EVTV with EVLW ( $r$ values $=0.86-0.96) .^{341314}$

In this human study, data from eight of the nine subjects are consistent with the data obtained in animal experiments. Although the actual direct agreement of EVTV with EVLW may not have been as close as some might wish, the strong linear association and excellent reproducibility (that is, ability to detect a $15 \%$ change in EVTV) argue for its application in clinical medical research. Because of this small sample size for human data, it is particularly worth noting that these data, when plotted with our published animal data ${ }^{314}$ show a very similar relationship between EVTV and lung water measurements (fig 3). The EVTV measurement at which frothing pulmonary oedema was noted in dogs $(>23 \mathrm{ml} / \mathrm{kg}$ ) also correlates well with our one subject $(23.2 \mathrm{ml} / \mathrm{kg})$ who had this degree of pulmonary oedema.

The one human subject in whom EVTV grossly underestimated lung water may have had a clinical condition that has not yet been adequately evaluated in an animal model. Most experimental models of lung water accumulation have included only homogeneous injuries (hydrostatic pulmonary oedema, lesions induced by oleic acid, endotoxin, and sepsis). Regional acid aspiration, contusion, and pneumonitis models have not been studied, and may have been responsible for the error observed in this subject. The EVTV measurement is, however, known not to be affected by atelectasis, another common clinical condition that may reduce regional pulmonary blood flow. ${ }^{12}$ Microsphere embolisation of the pulmonary vasculature has been shown to cause underestimation of lung water by the EVTV measurement, ${ }^{1112}$ and presumably any process that prevents transit of the thermal indicator through a sizable region of oedematous lung will produce the same error. The role of hypoxic pulmonary vasoconstriction in producing this error is not known.

The results of this clinical study support previous animal data and suggests that the thermal dye indicator dilution measurement provides a reliable estimate of extravascular lung water in diffuse pulmonary oedema states. In some clinical conditions of regional lung injury, however, this measurement may considerably underestimate lung water.

We gratefully acknowledge the assistance of Dr Lincoln Moses in analysing the data from this study, and the secretarial support of Mrs Marian Lykken. Part of this study was supported by grant No HL13108 from the National Institutes of Health.

\section{References}

1 Halperin BD, Feeley TW, Mihm FG, Chiles C, Guthaner DF, Blank NE. Evaluation of the portable chest roentgenogram for quantitating extravascular 
lung water in critically ill adults. Chest $1985 ; 88: 649-52$.

2 Lewis FR, Elings VB, Sturm JA. Beside measurement of lung water. J Surg Res 1979;27:250-61.

3 Mihm FG, Feeley TW, Rosenthal MH, Lewis F. Measurement of extravascular lung water in dogs using the thermal-green dye indicator dilution method. Anesthesiology 1982;57:116-22.

4 Holcroft JW, Trunkey DD, Carpenter MA. Excessive fluid administration in resuscitating baboons from hemorrhagic shock and an assessment of the thermodye technique for measuring extravascular lung water. Am J Surg 1978;135:412-6.

5 Bland JM, Altman DG. Statistical methods for assessing agreement between two methods of clinical measurement. Lancet 1986;:307-10.

6 Stetz CW, Miller RG, Kelly GE, Raffin TA. Reliability of the thermodilution method in the determination of cardiac output in clinical practice. Am Rev Respir Dis 1982;126:1001-4.

7 Fein A, Grossman RF, Jones JG, et al. Evaluation of transthoracic electrical-impedance in the diagnosis of pulmonary edema. Circulation 1979;60:1156-60.

8 Friedman M, Kaufman SH, Wilkins SA. Analysis of rebreathing measurements of pulmonary tissue volume in pulmonary edema. J Appl Physiol 1980;48:66-71.

9 Simon DS, Murray JF, Staub NC. Measurement of pulmonary edema in intact dogs by trans-thoracic gamma-ray attenuation. J Appl Physiol 1979;47:1228.

10 Chinard FP, Enns T. Transcapillary pulmonary exchange of water in the dog. Am J Physiol 1954; 178:197-202.

11 Oppenheimer L, Elings VB, Lewis FR. Thermal-dye lung water measurements: effects of edema and embolization. J Surg Res 1979;26:504-12.

12 Beckett RC, Gray BA. Effects of atelectasis and embolization on extravascular thermal volume of the lung. J Appl Phys 1982;53:1614-9.

13 Lewis FR, Elings VB, Hill SL, Christensen JM. The measurement of extravascular lung water by thermalgreen dye indicator dilution. Ann NY Acad Sci 1982;384:394-410

14 Saul GM, Feeley TW, Mihm FG. The effect of graded 옥 administration of PEEP on lung water in non- cardiogenic pulmonary edema. Crit Care Med $\stackrel{c}{\stackrel{c}{9}}$ 1982;10:667-9. 